\title{
A Novel Portable Real-Time Low-Cost Sleep Apnea Monitoring System based on the Global System for Mobile Communications (GSM) Network
}

\author{
Harun SÜMBÜL ${ }^{1}$ - Ahmet Hayrettin YÜZER ${ }^{2}$ Kazım Şekeroğlu ${ }^{3}$
}

Received: 15 March 2021 / Accepted: 17 December 2021 / Published online: 14 January 2022

(c) International Federation for Medical and Biological Engineering 2021

\begin{abstract}
Background and objective Continuous monitoring of breathing activity plays a vital role in the detection of respiratory-based diseases (SA, COPD, etc.). Sleep Apnea (SA) is characterized by recurrent upper airway obstruction during sleep associated with arterial blood desaturation, sympathetic nervous system activation, and cardiovascular impairment. Untreated patients with SA have increased mortality rates compared to the general population. This study aims to design a remote monitoring system for sleep apnea to ensure patient safety and ease the workload of doctors in the Covid-19 era.

Methods This study aims to design a remote monitoring system for sleep apnea to ensure patient safety and ease the workload of doctors. Our study focuses on a novel portable real-time low-cost sleep apnea monitoring system utilizing the GSM network (GSM Shield Sim900a). Proposed system is a remote monitoring and patient tracking system to detect the apnea event in real time, and to provide information of the sleep position, pulse, and respiratory and oxygen saturation to the medical specialists $\left(\mathrm{SpO}_{2}\right)$ by establishing a direct contact. As soon as an abnormal condition is detected in the light of these parameters, the condition is reported (instant or in the form of short reports after sleep) to the patient relatives, the doctor's mobile telephone or to the emergency medical centers (EMCs) through a GSM network to handle the case depending on the patient's emergency condition.

Results A study group was formed of six patients for monitoring apnea events (three males and three females) between the ages of 20 and 60. The patients in the study group have sleep apnea (SA) in different grades. All the apnea events were detected, and all the patients were successfully alerted. Also, the patient parameters were successfully sent to all patient relatives. Patients who could not get out of apnea were called through the CALL feature, and they were informed about their ongoing apnea event and told that intervention was necessary. The proposed system is tested on six patients. The beginning moment of apnea was successfully detected and the SMS/CALL feature was successfully activated without delay. During the testing, it has been observed that while some of the patients start breathing after the first SMS, some others needed the second or the third SMS. According to the measurement result, the maximum breathless time is $46 \mathrm{~s}$ among the patients, and a SMS is sent every $15 \mathrm{~s}$. In addition, in cases where the patient was breathless for a long time, the CALL feature was actively sought from the relatives of the patient and enabled him to intervene. The proposed monitoring system could be used in both clinical and home settings.

Conclusions The monitoring of a patient in real time allows to intervene in any unexpected circumstances about the patient. The proposed work uses an acceleration sensor as a reliable method of the sleep apnea for monitoring and prevention. The developed device is more economical, comfortable, and convenient than existing systems not only for the patients but also for the doctors. The patients can easily use this device in their home environment, so which could yield a more comfortable, easy to use, cost-effective, and long-term breathing monitoring system for healthcare applications.
\end{abstract}

Keywords Sleep Apnea $\cdot$ GSM $\cdot$ SMS/CALL $\cdot$ Wearable devices $\cdot$ Acceleration sensor

Harun SÜMBÜL

harun.sumbul@omu.edu.tr

Extended author information available on the last page of the article 


\section{Introduction}

Characterizing upper airway obstruction during normal sleep could give us an important data about the types of the disease related to breathing and sleep disorders. Observing the features of the upper airway dynamics is an important step at the treatment planning. Because, the knowledge of mutual patterns of the upper airway dynamics of respiratory events may lead to a new diagnostic method for patient-specific treatment planning $[1,2]$.

Sleep apnea (SA) is characterized by recurrent upper airway obstruction during sleep associated with arterial blood desaturation, sympathetic nervous system activation, and cardiovascular impairment. Untreated patients with SA have increased mortality rates compared to the general population [3]. SA, characterized by repetitive breathing stops during sleep, is highly common, and it is a difficult disease to detect [4]. Sleep apnea is known to be a respiratory disease and approximately affecting $10 \%$ of the adult population [5]. Sleep-disordered breathing in elderly population is more prevalent, and it involves a longer event than young and middle-aged groups [6]. It can also be seen with other diseases like epilepsy [7], obesity [8], and venous thromboembolism (VTE) [9] and trigger them. So, the people suffering from SA cannot feel the benefits of a restful sleep due to effects caused by a collapse (total or partial) of the upper airways of the respiratory system [10].

The importance and the need for respirators and ventilators have shown once again itself due to the new coronavirus (Covid-19) pandemic, which has recently spread around the world and has been declared as a Global Pandemic (worldwide epidemic) by the WHO (World Health Organization.)

Although it is not known exactly how the coronavirus may react in which person, some people are at greater risk with the coronavirus and they are more affected by Covid-19. Although SA is not associated with the risk of contracting Covid-19, it is a severe risk factor for Covid19. In contrast, among Covid-19 positive patients, SA is associated with higher risk for hospitalization [11].

The relationship between SA and the risk of Covid-19 infection and the need for hospitalization and respiratory failure has revealed that patients with Apnea have an eightfold higher risk. Accordingly, among patients with Covid19 infection, it has also been reported that SA nearly doubles the risk of hospitalization and respiratory failure [12].

It was also concluded that sleep apnea increases the risk of Covid-19 and may contribute to poor outcomes by worsening or causing lung damage. Therefore, there is a significant relationship between SA and death from Covid-19 [13].

$\mathrm{SA}$ is an additional risk for serious disease development in patients with Covid-19, and patients with SA have been observed to have an increased risk of developing adult respiratory distress syndrome following non-cardiac surgery [14].

It is known that the intensity of using polysomnography (PSG) in sleep laboratories for the diagnosis of SA before the Covid-19 pandemic has decreased significantly compared to its use during the pandemic. In addition, staff levels in sleep medicine services decreased significantly compared to pre-pandemic staff levels, and a significant increase in telemedicine services was observed. In light of the Covid-19 pandemic, it became obvious that there is a need to revise existing technologies for SA and use new and different medical monitoring devices [15].

During the Covid-19 outbreak, non-emergency sleep laboratory services are delayed in many settings due to the limited availability of the healthcare resources. Therefore, it has become imperative to consider telemedicine as a potentially effective alternative for early detection and intervention and to prevent emergencies in inadequate SA monitoring and treatment during the current pandemic [16]. The use of telematic techniques is useful for establishing a diagnostic and therapeutic strategy for SA [17]. There are a number of papers published in the literature about Electronic Health Records (EHR) systems such as Al-Zubaidie [18], RiveroGarcía[19], and Dubovitskaya[20]. The common point of these publications is the suggestion to find a solution to preventing legitimate users from exceeding their privileges as well as preventing attackers from accessing patient data in the EHR system. It is also stated in these publications that the actions to be taken to protect personal health data have disadvantages such as delays and extra costs in the system. In this study, the focus is on the electronic circuit and system design rather than data security, since the cost-efficient system design and emergency intervention may be required especially in case of apnea and death risk.

Telemedicine can play a vital role in the monitoring and treatment of SA and similar diseases. It is obvious that some precautions should be taken for what should be seen in sleep clinics. This is a risky and troublesome situation. Therefore, new procedures and new remote monitoring medical devices are required to monitor such patients [21, 22].

Apnea was defined as an absence of airflow for $>10 \mathrm{~s}$. There are three types of SA; obstructive sleep apnea (OSA), central sleep apnea (CSA), and mixed sleep apnea (MSA). OSA is defined as the absence of nasal airflow for $>10 \mathrm{~s}$ associated with inspiratory effort. CSA is defined as with $>50 \%$ of the event labeled as the central type rather than the obstructive type. MSA is a combination of the previous two types of apnea [23]. Anatomically based treatments are not a complete solution for apnea.

The current gold standard assessment for screening SA is PSG. PSG shows frequent isolated apnea that occurs in non-rapid eye movement sleep. PSG requires an overnight 
stay in a sleep laboratory where the patients are equipped more than 18 sensors. The complex nature of PSG, its high cost, requires expert knowledge and limited facilities to run PSG which have resulted in long waiting list [24]. Therefore, there are many studies about a novel solution to sleep apnea detection in the literature [25-28]. However, in 2017, the AASM (American Academy of Sleep Medicine) published and approved a guide on the use of home sleep apnea tests compared to sleep laboratory-based PSG and concluded that although available literature was still insufficient to propose home testing for the diagnosis of SA, further research in this area should be encouraged [29]. The following statements were used for home sleep apnea test (HSAT); "If an appropriate HSAT device could be shown to be a suitable alternative to PSG, it could potentially circumvent many of these barriers and improve the quality and efficiency of care for pediatric patients with SA."

There are numerous vital studies for monitoring patients at home, and these studies are used by people with different needs, such as elderly or disabled people, and/or with chronic diseases, among other such as in [30-33].

As reported earlier, in other studies, an intelligent selfadjusting pillow is proposed for apnea event detection [34], a sound monitoring system is proposed in order to detect an apnea event by using a smartphone [35], and a new telemedicine system for remote monitoring of CPAP therapy [36].

There have been several studies based on GSM to devise and monitor breathing activity during sleep. Iovanovici et al. [37] presented architecture for monitoring of sleep disorders. But the proposed solution is integrated via a set of web services into the server and is currently under the test phase, and it is not available for public use.

In the other study, a support vector classifier (SVC) was used to extract feature sets and detect apnea episodes from the patient's single-channel night ECG. Android operating system (OS)-based universal mobile telecommunication system/mobile communication (GSM/UMTS) was preferred as the computing platform [38].

Al-Naji et al. [39] aim to detect the irregular breathing syndromes, including central apnea by tracking of thorax moves. The authors monitored patient status from different distances using an ultrasonic PING sensor and microcontroller. However, the patient's sleeping position during sleep cannot be compatible with the sensor used. In addition, Gharghan et al. [40] developed a human vital signs monitoring system (HVSMS) that includes Global Positioning System (GPS), GSM, and acceleration sensors. But this study mostly focused on power consumption and battery life of the system, and the main purpose of the study was to minimize the power consumption.

Sara Balderas-Diaz et al. [41] developed a service-based system for diagnosis of patients with sleep apnea-hypopnea. The proposed system allows a greater outreach to the population and reducing waiting lists in hospitals. However, the proposed system needs to be experimented and evaluated with different users in order to analyze the benefits and address the potential improvements.

Our study focuses on a novel portable real-time low-cost sleep apnea monitoring system utilizing the GSM network in the Covid-19 era. The proposed system is a remote monitoring and telemedicine system to detect the apnea event in real time, and to provide information of the sleep position, pulse, respiratory and oxygen saturation to the medical specialists by establishing a direct contact. As soon as abnormal conditions are detected in the light of these parameters, the condition is reported (instant or in the form of short reports after sleep) to the patient relatives, the doctor's mobile telephone or to the emergency medical centers (EMCs) through a GSM network to handle the case depending on the patient's emergency condition. This study aims to design a remote monitoring system for sleep apnea to ensure patient safety and ease the workload of doctors in the Covid-19 era.

\section{Material and Method}

The accuracy of wearable real-time SA measurement system and detection algorithm based on the acceleration sensor was clinically tested in our previous study $[42,43]$. The contributions of this study can be summarized as follows:

1. A novel portable real-time low-cost sleep apnea monitoring system was designed and implemented to telemonitor apnea patients in their home and detects the events of a patient with a large communication range using the GSM network.

2. Newly developed telemedicine system can detect the apnea events and send this information (momentary or in the form of short reports after sleep) to the patient relatives, the doctor's mobile telephone or to the emergency medical centers (EMCs) through a GSM network.

3. The system has been strengthened with additional equipment such as air pressure sensor (MPX10DP), pulse (Heart Rate) sensor, blood oxygen saturation sensor (Max30100), and GSM (SIM900A chip). The system uses breathing data, respiratory-related movements, sleep positions, pulse information, and $\mathrm{SpO}_{2}$. The architecture of the proposed microcontroller based diagnostic system and electrical circuit are shown in Fig. 1 and Fig. 2, respectively.

Assessment of the validity of the proposed system for monitoring apnea events was performed on the study group between the ages of 20 and 60 . The study group consists of six patients (three males (50\%) and three females (50\%)) with different characteristics ([mean] age, 36.3; height, $169.6 \mathrm{~cm}$; and body weight, $81.4 \mathrm{~kg}$ ). General characteristics of the study groups formed are explained in Ref [42]. The patients in the study group have sleep apnea in varying 


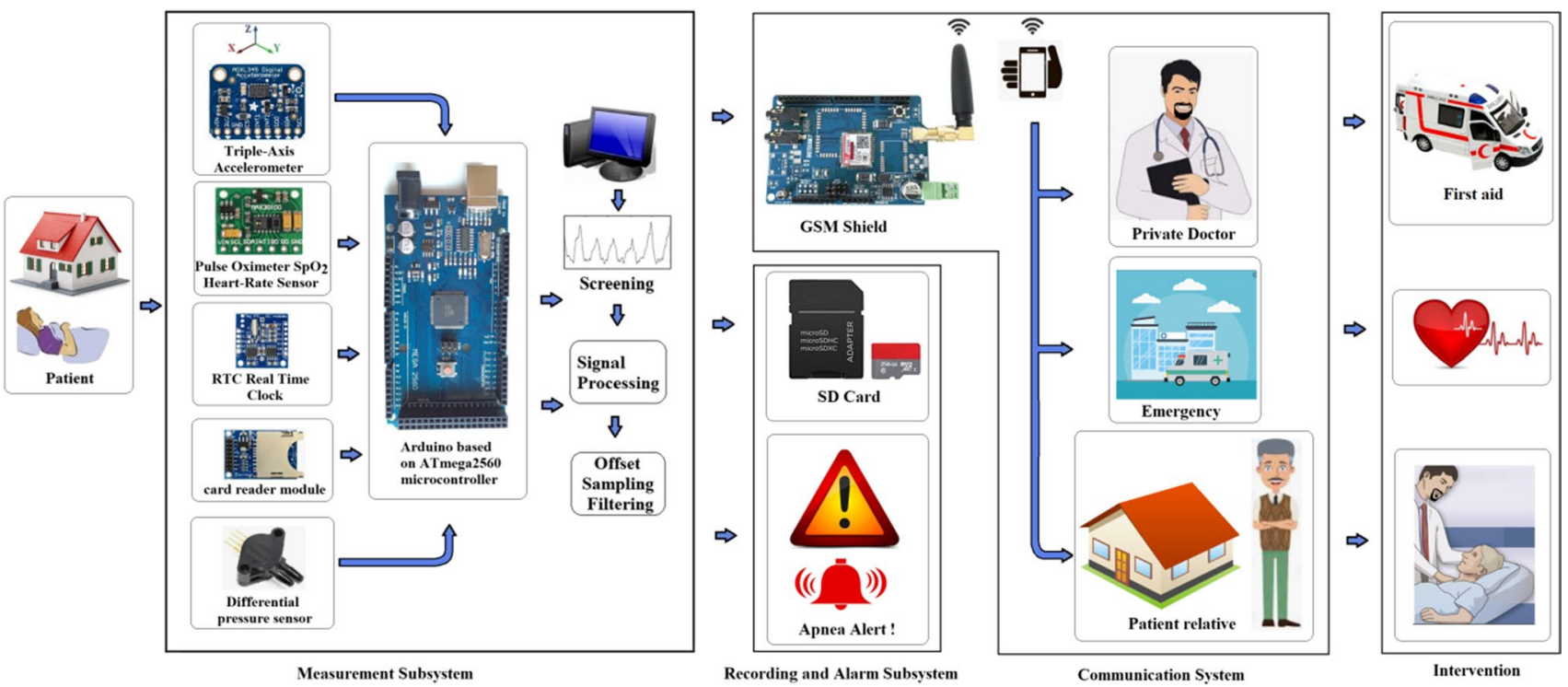

Fig. 1 Monitoring system architecture

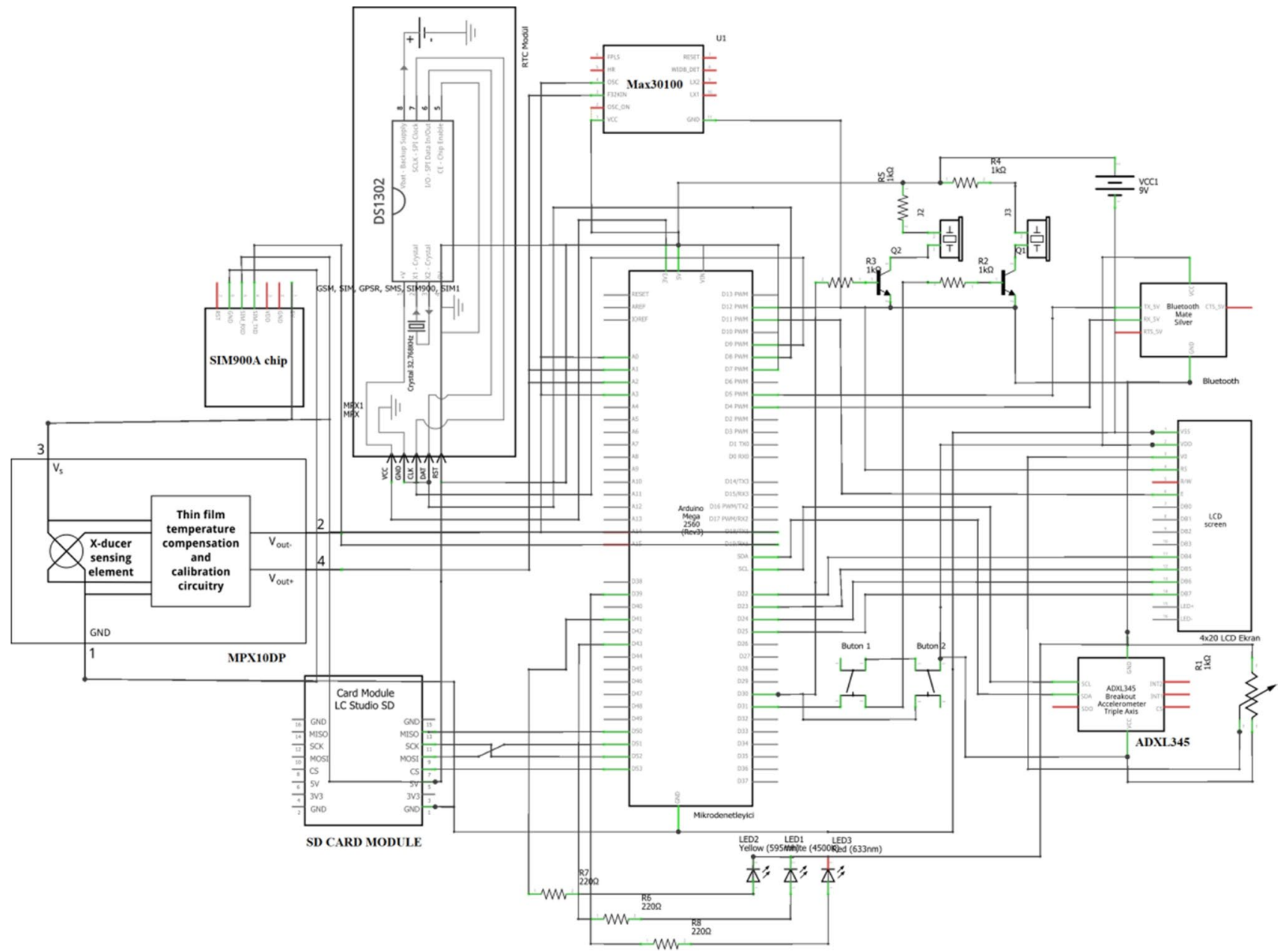

Fig. 2 Electrical circuit of system 
grades (mild OSA, middle OSA, and heavy OSA) and randomly selected from the hospital. The study adhered to the Declaration of Helsinki ethical principle. The protocol was approved by the ethics committee of Ondokuz Mayis University, and the patient informing form for all subjects was obtained after a full explanation of the research procedures before commencing the experiment.

\section{Measurement Subsystem}

All data measured by the sensors (acceleration, heart rate, breathing, and $\mathrm{SpO}_{2}$ ) are recorded on the SD card or can be transferred to the computer via USB. The circuit board of the measurement and monitoring system is shown in Fig. 3. The sensors are connected to the microcontroller by a wire.

Respiratory air flow and volume data can be measured by the differential air pressure sensor (MPX10DP) which provides a linear voltage output and by using a nasal apparatus with headband. MPX10DP is less affected by temperature, small in size, cheaper than its counterparts and durable for long periods of duration. So, it has been used in many respiratory applications $[44,45]$.

MAX30100 (Maxim Integrated, USA) is an integrated pulse oximetry and heart-rate noninvasive measurement biosensor. This sensor consists of red and infrared led (red led with a wavelength of $660 \mathrm{~nm}$ and infrared led with $880 \mathrm{~nm}$ wavelength), an optical receiver and low-noise analog signal processing, as well as a built in $50 \mathrm{~Hz}$ filter. The heart rate is being measured when only infrared LED is on. In order to measure $\mathrm{SpO}_{2}$, both LEDs must be turned on.

According to the working principle of this sensor, the light sources and optical receiver are placed side by side, and signal measurements are calculated from reflected light intensity and compared the light absorption characteristics of blood under these wavelengths [46, 47].

MAX30100 sensor is attached on the forefinger clip, which can fit the thumb to allow easy and simple measurement. Patient's forefinger will be put on the red and infrared LED which is located on the surface of the sensor.

The MAX30100 is configured by using inter-integrated circuit $\left(\mathrm{I}^{2} \mathrm{C}\right)$ protocol. This protocol can be set in many parameters (analog numerical cycle resolution, sampling rate, reporting time, and the red and infrared led current values) that regulate the operation of the sensor. The most suitable parameters for the sensor were calibrated according to the literature [48]. Figure 4 also shows the structure of the oxygen saturation and heart-rate detection.

The flow card of the system is shown in Fig. 5.

\section{Recording and Alert Subsystem}

Wearable real-time sleep apnea patient alerting system based on the acceleration sensor was experimentally tested as presented in our previous study [42]. The patients in that study group have sleep apnea (SA) in different grades. All the apnea events were detected, and all the patients were successfully alerted. In addition, the proposed system is able to detect the supine lying position, which is the most common apnea position in apnea patients. Furthermore, the proposed system aims to inform and interfere with different people over the GSM network when the patient cannot wake up.

\section{Communication Subsystem}

Today, with the rapid development of wireless communication technology, mobile phones have become usable in many systems around the world (health, fall tracking, military, medical, transportation, etc.) $[49,50]$. Our wireless

Fig. 4 Basic working principle of MAX30100 Sensor
Fig. 3 Hardware of measurement and monitoring system
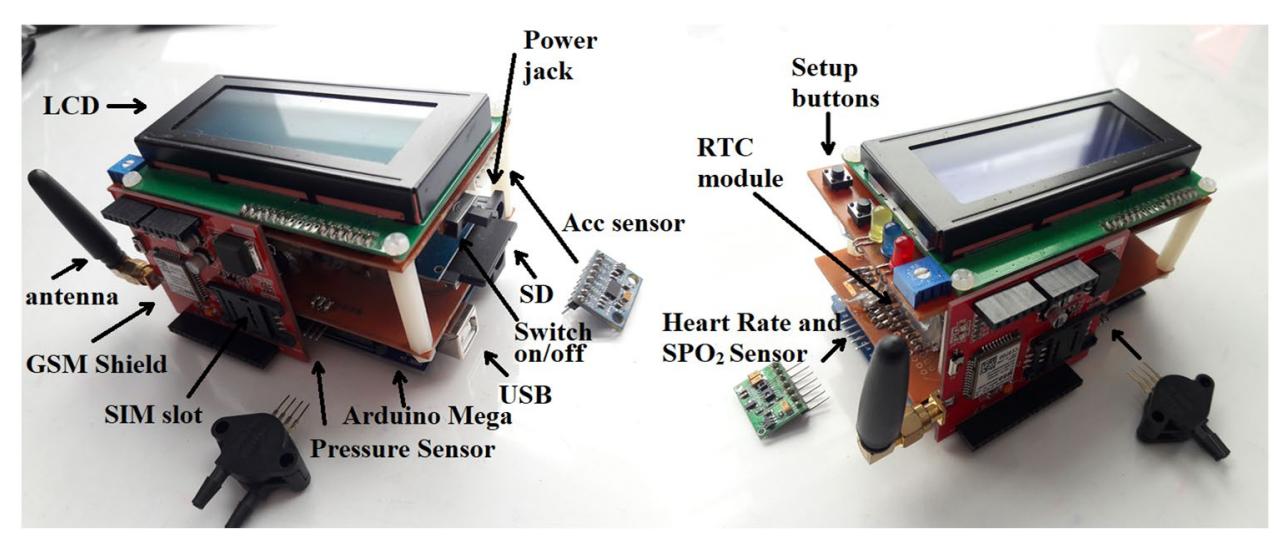
Fig. 5 Flow card of the system

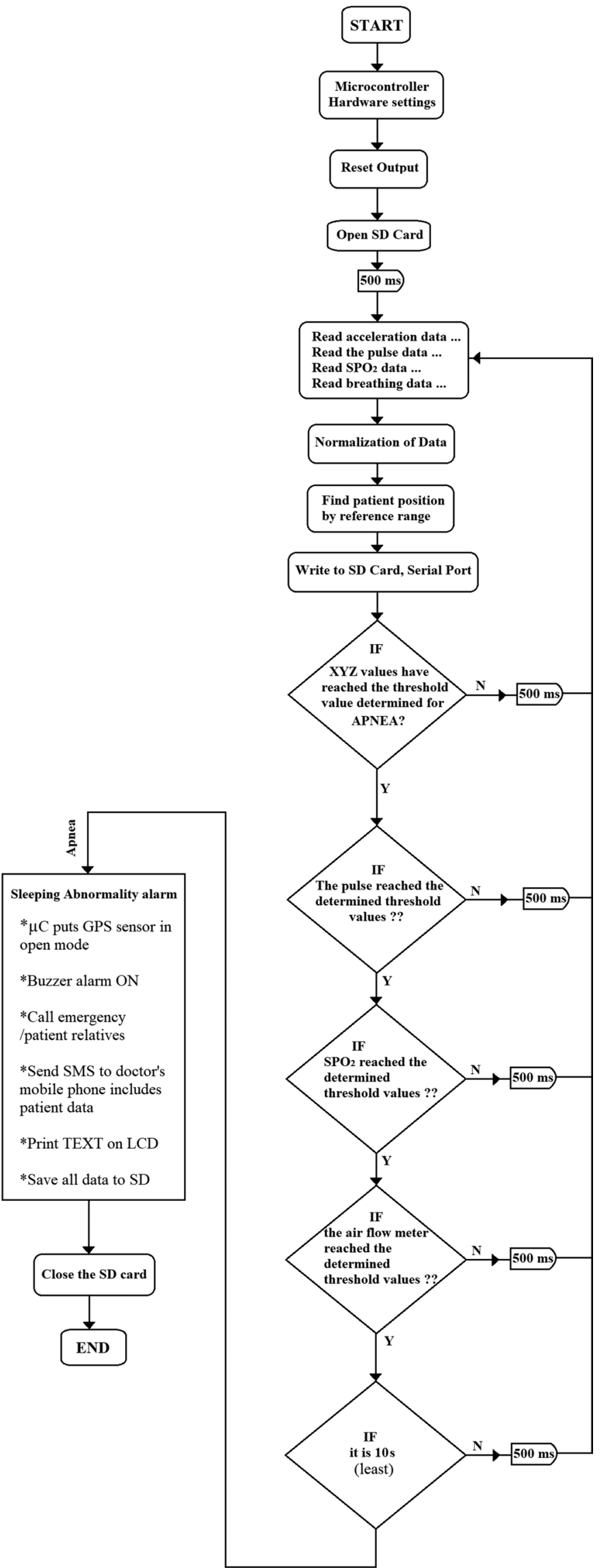




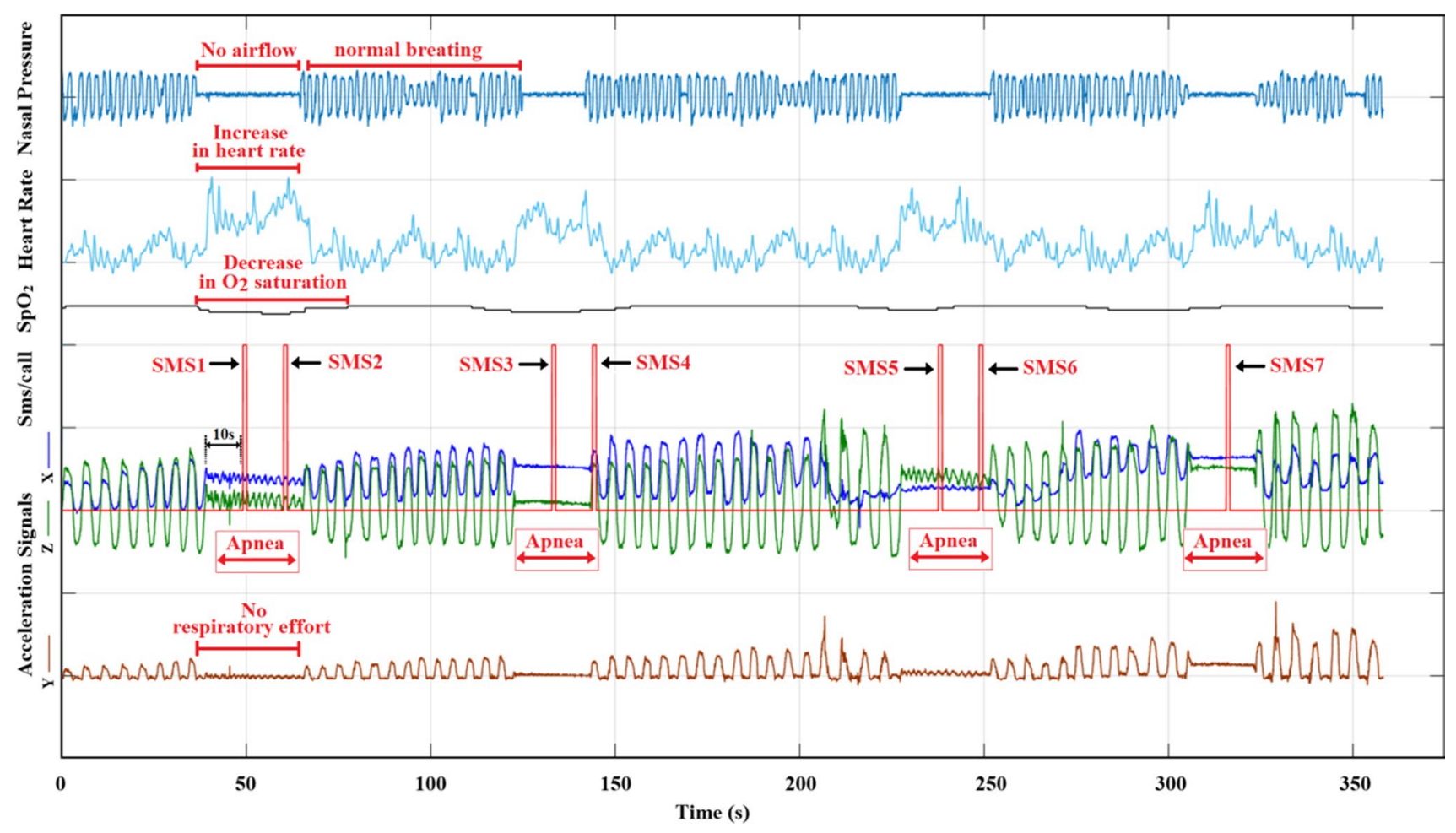

Fig. 6 Monitoring of apnea episodes, SMS case, and normal-abnormal breathing

communication subsystem has a SIM900A chip, a SIM (Subscriber Identity Module) card and a dual band antenna (SMA antenna). It works on frequencies $900 / 1800 \mathrm{MHz}$ with the service provider with the help of SIM card. The chip can search these two bands automatically. GSM shield enables an Arduino board to connect to the internet, make voice calls, or send and receive SMS using the GPRS wireless network. This shield is compatible with Arduino mega.

The commands are sent from the microcontroller using USART (Universal Synchronous Asynchronous Receiver Transmitter) serial communication [51]. GSM shield supports communication through RS232 with DB9 Connector, TTL Pins. Its operation temperature is between $-40{ }^{\circ} \mathrm{C}$ and $+80^{\circ} \mathrm{C}$.

GSM shield must be fed externally (AC and DC solder points also available on board). In case the external source is not connected, the current drawn from the USB is insufficient when it finds a network from GSM shield. Another point to be considered here is that the SIM card to be inserted into GSM shield should not ask for a pin code. For this reason, when the SIM card is inserted in the phone, it is necessary to enter the SIM settings and not to ask for a password.

When the apnea event detected, an SMS will be sent automatically to the patient's privative doctor or relatives to be informed about the patient's condition. SMS consists of the respiratory data, pulse, $\mathrm{SpO}_{2}$, accelerations, lying position, recording information, and total apnea count.

If the patient is unable to get out of the apnea (despite the alert system) or if the apnea event reaches a serious condition, instead of SMS, it goes directly to call mode and thus offers the patient a chance to intervene immediately. The system can also call the emergency service and ask for help with a voice message recorded before.

Thus, thanks to this system, it is possible to record and monitor sleep during the night and provide the opportunity to intervene the patient in emergency situations.

\section{Experimental Results}

Figure 6 is a part of the real data from our sleep apnea monitoring system based on the GSM network device. It measures percentage of oxygen $\left(\mathrm{SpO}_{2}\right)$, pulse rate (in heart beats per minute), accelerations on the diaphragm (on the XYZ axis), and nasal pressure (through a mask).

At the moment in time that no airflow and no respiratory effort for $10 \mathrm{~s}$, oxygen levels are steady above $95 \%$ and the heart rate is at a restful 58 beats per minute (apneic event). The waveform data part above is (about $7 \mathrm{~min}$ view) from a person with obstructive sleep apnea (OSA). OSA occurs when the soft palate and tongue relax, collapsing the airflow for at least $10 \mathrm{~s}$. The oxygen levels become erratic 
Fig. 7 Apnea event detection and notification by SMS for the patients (a) $\mathrm{H} 1$, (b) $\mathrm{H} 2$, (c) $\mathrm{H} 3$, (d) $\mathrm{H} 4$, (e) $\mathrm{H} 5$, (f) $\mathrm{H} 6$
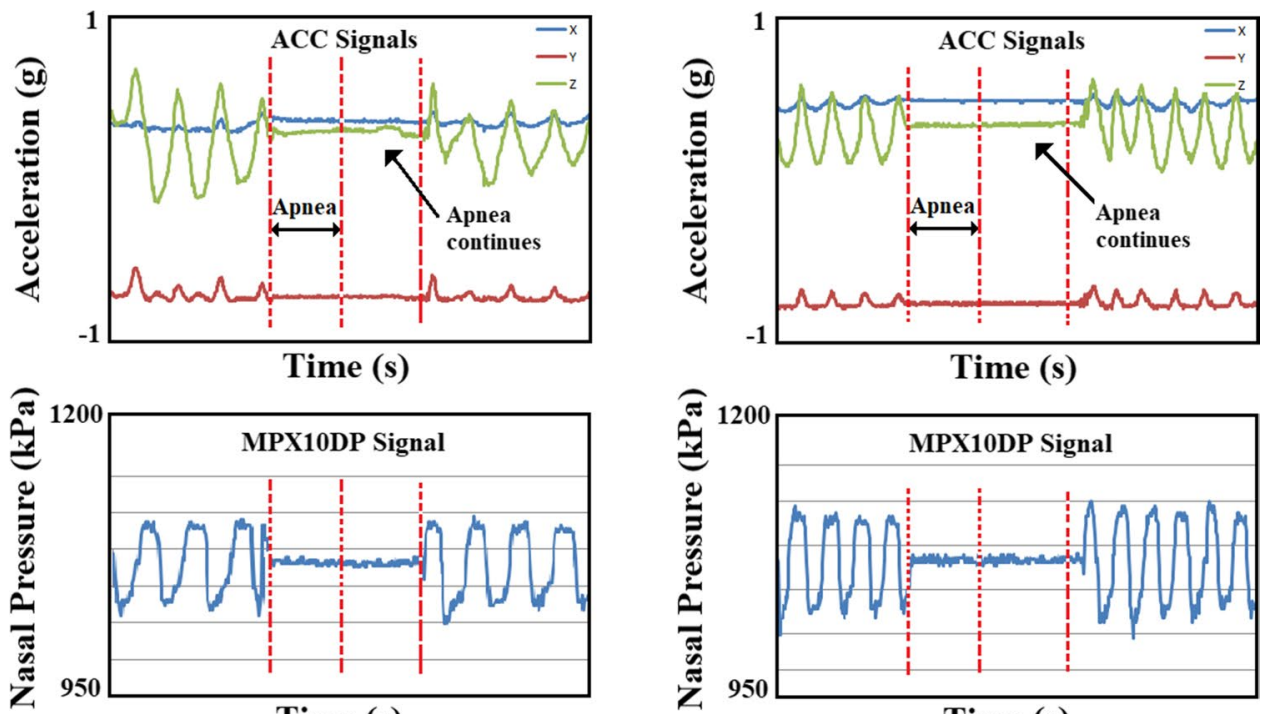

Time (s)

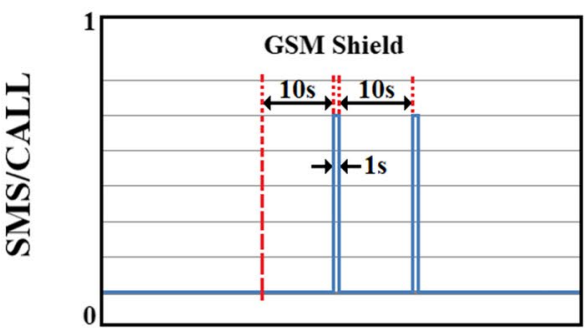

Time (s)

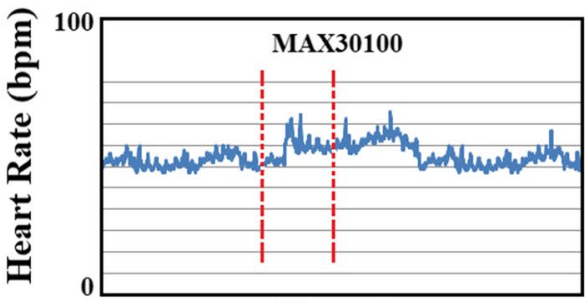

Time (s)

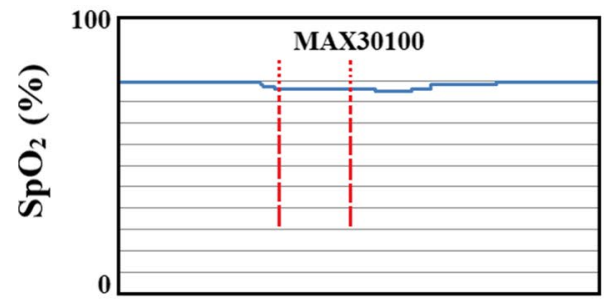

Time (s)

(a)

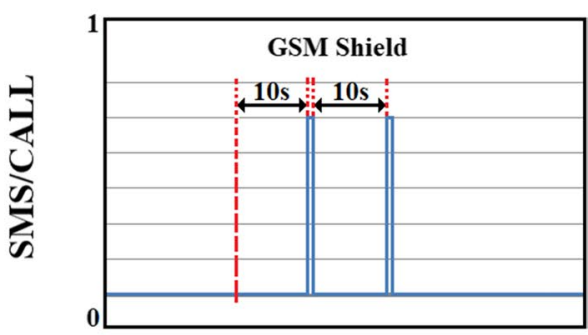

Time (s)

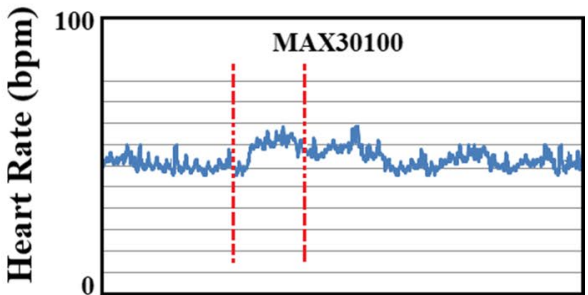

Time (s)

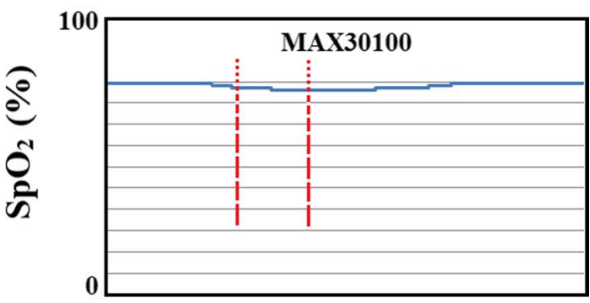

Time (s)

(b) and decrease below $95 \%$. The pulse rate can race above 80 beats per minute. When oxygen saturation levels drop, the heart responds by increasing the heart rate.

When Fig. 5 is carefully examined, it can be seen that following the apnea episode, the oxygen level rises in the next breath, the effort of breathing increases, the diaphragm movement occurs, and the heart rate slows.
As soon as apnea was detected (at least $10 \mathrm{~s}$ breathless), the system sends the first text message to the registered numbers (SMS1). The time allocated to send the message is set to $1 \mathrm{~s}$ (considering the possibility of delays due to GSM operators). When the patient remains breathless, a second text message is sent in the 10th second in progress (SMS2). If the patient still cannot wake up, however, the device will operate in call mode and will call the registered 
Fig. 7 (continued)
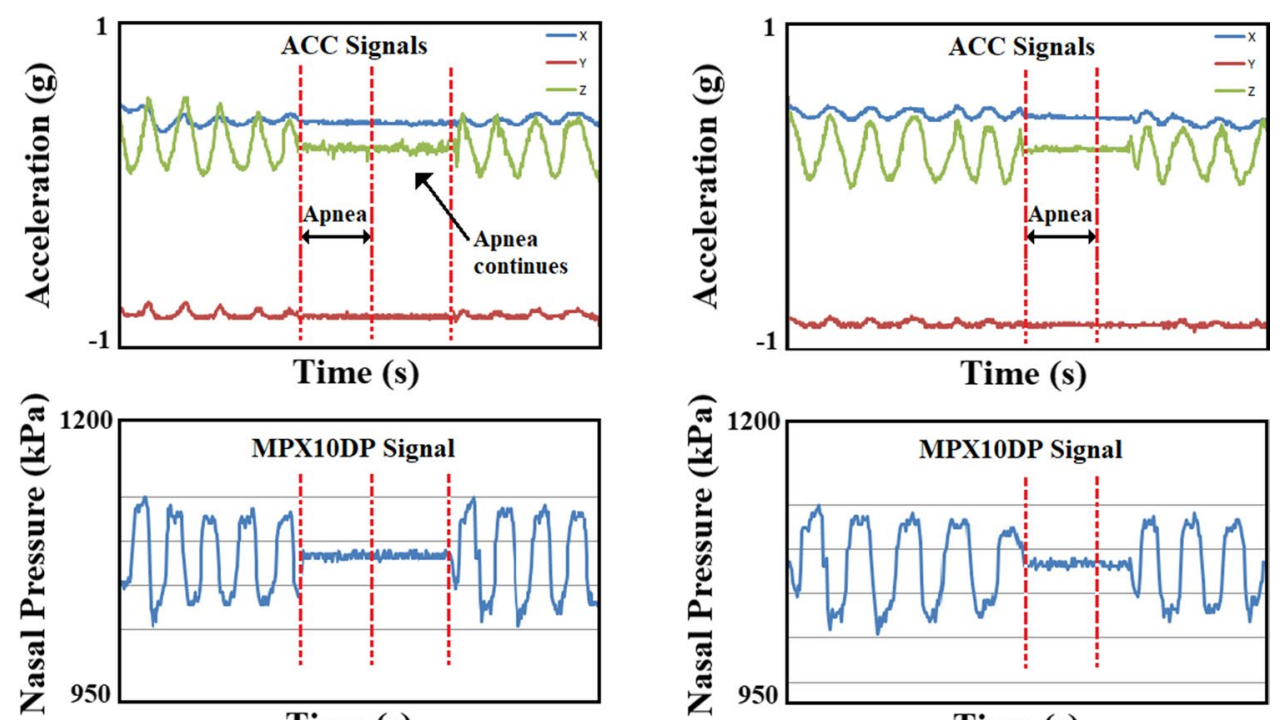

Time (s)

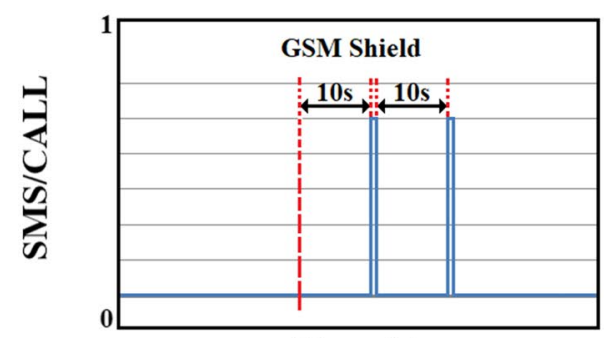

Time (s)

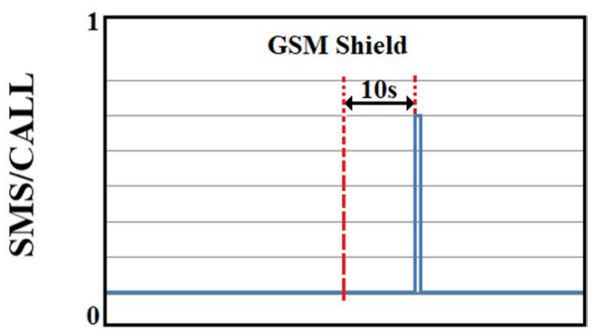

Time (s)

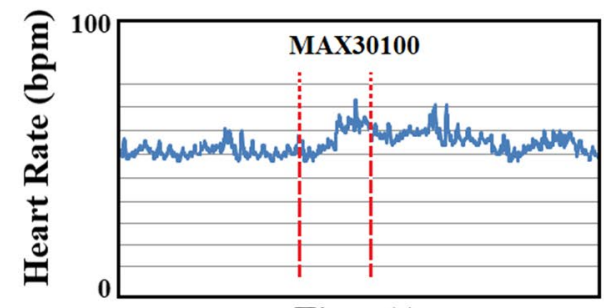

Time (s)

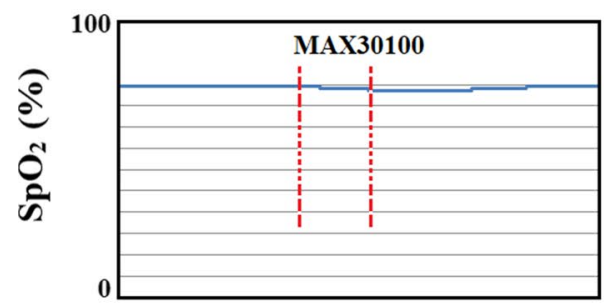

Time (s)

(c)

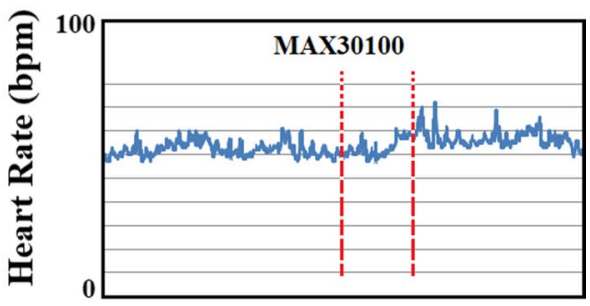

Time (s)

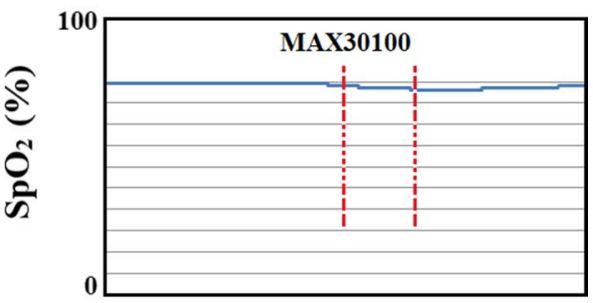

Time (s)

(d)

numbers to transmit the previously recorded voice message (CALL1).

In the graphic in Fig. 6, there is no information showing the call status since no patient was observed during the recording. However, this feature was tried during the test phase demo studies, and it was observed that it successfully runs.
Performance of real-time low-cost sleep apnea monitoring system based on the GSM network for the patients $\left(\mathrm{H}_{1}\right.$, $\mathrm{H}_{2}, \mathrm{H}_{3}, \mathrm{H}_{4}, \mathrm{H}_{5}$, and $\mathrm{H}_{6}$ ) is given in Fig. 7 separately. The system, equipped with several peripheral units, can detect apnea events successfully for the all patients. This means that the system can monitor the apnea situation for any patients in real time. After being breathless for $10 \mathrm{~s}$, the system sends 
Fig. 7 (continued)
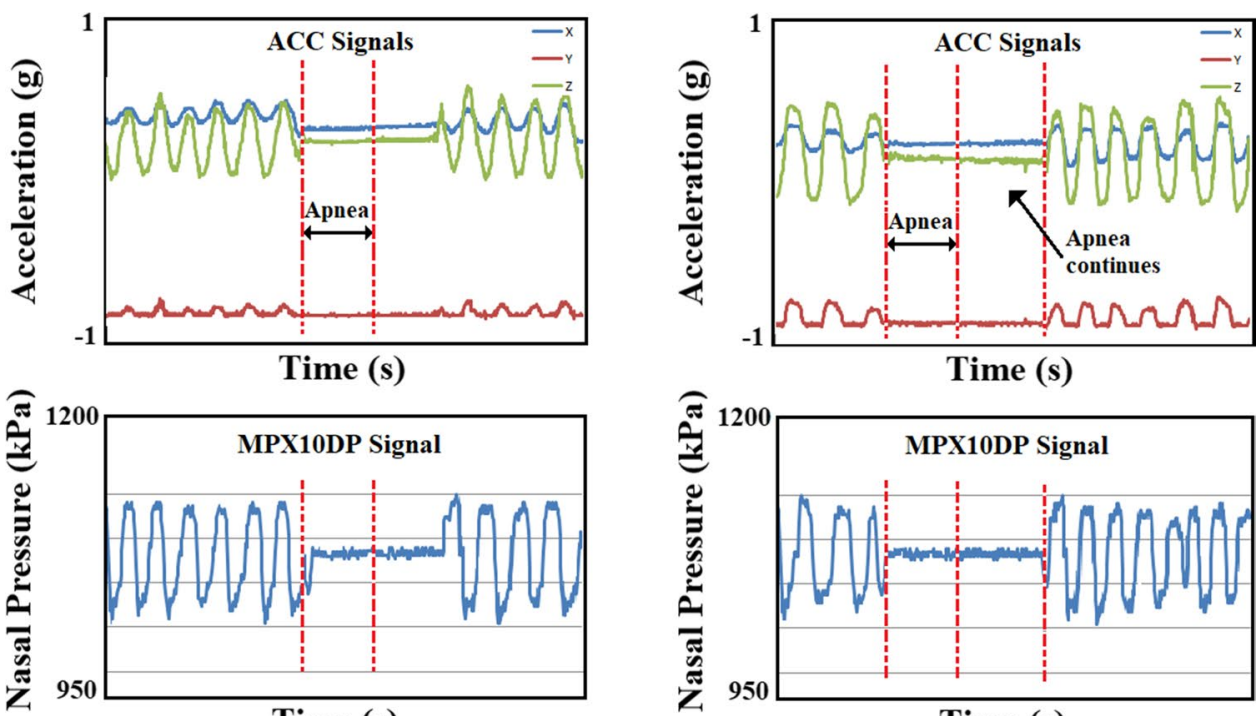

Time (s)

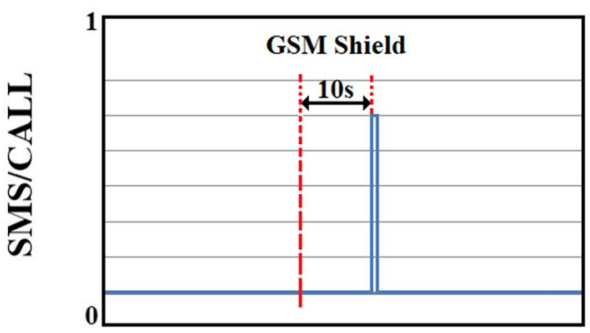

Time (s)

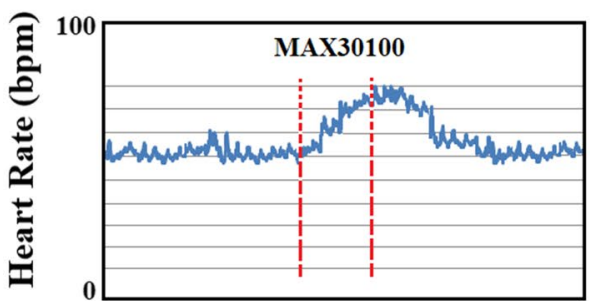

Time (s)

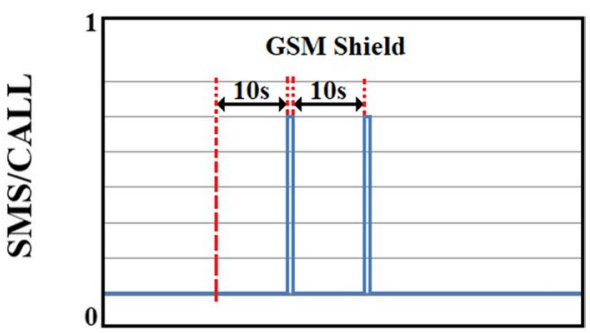

Time (s)

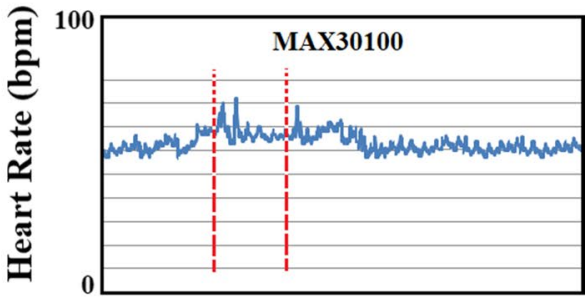

Time (s)

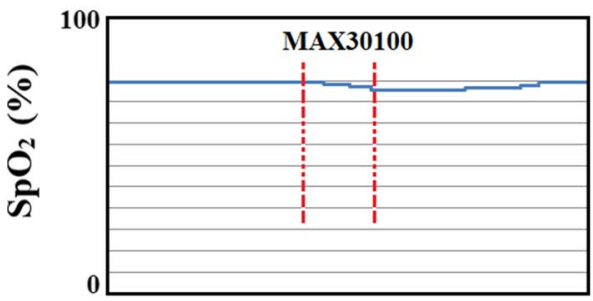

Time (s)

(e)

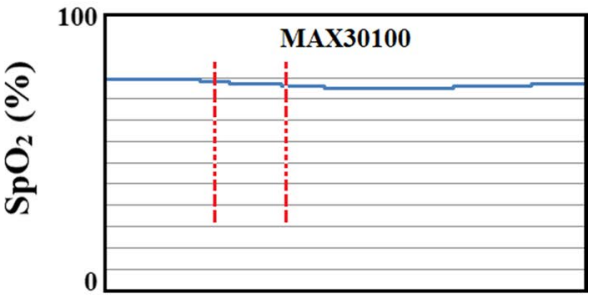

Time (s)

(f)

the first SMS to the registered number. After the second $10 \mathrm{~s}$, the second SMS is sent.

To test the CALL feature of the developed system, one healthy subject (26 years, male) was firstly asked to perform normal and abnormal respiration for a period of two minutes. Then, the subject wore peripherals belonging to the device (accelerometer over the abdominal region, air pressure sensor, pulse (heart rate) and blood oxygen saturation sensor, and GSM (SIM900A chip). The subject was lied in the supine position (because apnea is mostly in this position), and he was firstly asked to breathe normally for $15 \mathrm{~s}$ and then hold his breath for $15 \mathrm{~s}$ followed by slow breathing for $15 \mathrm{~s}$. This performance was repeated 3 times. The breathing signal was recorded using developed device and analyzed. Figure 8 shows an example of SMS. 
Fig. 8 Apnea SMS data

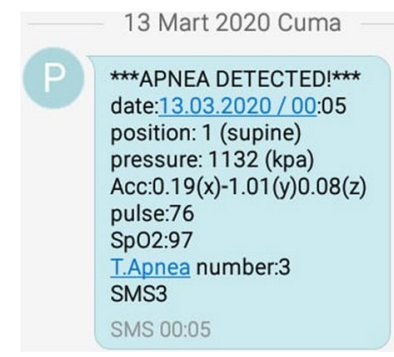

After $10 \mathrm{~s}$, the third SMS was sent, and instead of sending messages, the CALL feature was activated and called the registered number in the 40th second. Figure 9 shows the working graph of CALL procedure.

Thus, it is obvious that our proposed monitoring system could successfully and effectively detect the apnea events and could send an SMS when the breathing signal falls outside the normal range or when breathing stopped or became irregular.

As a result, in this study, many parameters about sleep apnea monitoring such as heart rate, beats per minute, apnea times, lying position data, the total number of apnea events and total sleep time in bed, acceleration data, and $\mathrm{SpO}_{2}$ were measured and recorded on an SD card successfully. All the apnea events were successfully detected, and all the patients' relatives were successfully informed by calling or sending a SMS.

\section{Discussion}

This work proposes a sleep monitoring system based on the Global System for Mobile Communications (GSM) network containing an acceleration sensor as a reliable method of the sleep apnea screening. One of the most important contributions of this study is the ability to send instant SMS about the patient's condition and to give voice notification by calling the previously registered people in situations that require urgent intervention. This property is essential not only to warn the elderly, disabled, or pediatric patients but also for the patients and their relatives. Also, this system gives an opportunity to remotely monitor the patients at their home and inform the doctors in case of an apnea event during the night. The proposed system provides a versatile, useful, practical, low-cost, and lifesaving solutions better than the most other existing methods for monitoring of sleep conditions.

\section{Conclusions}

Continuous monitoring of breathing activity plays a vital role in the detection of respiratory-based diseases (SA, COPD, etc.).

This study has presented the safe, portable, and highly accurate vital sign monitoring system which is designed to serve home-based monitoring of human vital signs that contain pulse oximetry $\left(\mathrm{SpO}_{2}\right)$, differential air pressure sensor (MPX10DP), and heart rate signal measures by using MAX30100 sensor.

Our system is integrated with the GSM network to display vital sign monitoring result in real time, and auto-send notification in case of any abnormality is detected. Thus, based on the created algorithm, it was possible to receive information about the patient's condition remotely either by SMS or by calling (CALL). Real-time monitoring of a patient allows the patient to intervene in extra cases.

In this study, during the tests performed on six patients, the onset of an apnea event was successfully detected, and the SMS/CALL feature was successfully activated without delay. While recording, it has been observed that some of the patients start breathing after the first SMS, whereas some others needed the second or the third SMS. According to the measurement result, the maximum breathless time is $46 \mathrm{~s}$ among the patients, and a SMS is sent every $15 \mathrm{~s}$. In addition, in cases where the patient was breathless for a long time, the CALL feature was actively sought from the relatives of the patient and enabled him to intervene. Developed portable real-time low-cost sleep apnea monitoring system based on the GSM network is expected to get an important place in the biomedical device technology with the ability to alert the patients as well as provide instant information

Fig. 9 CALL event data

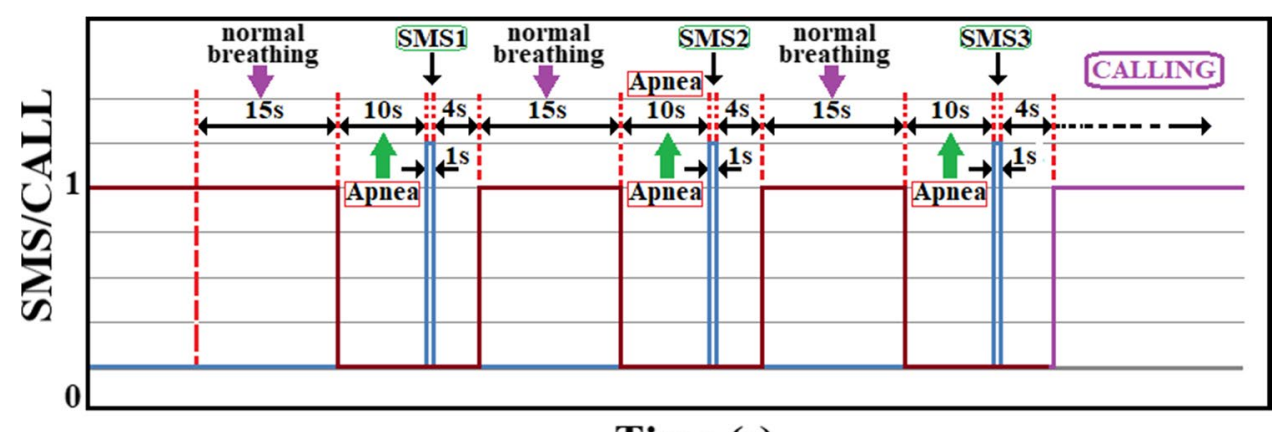

Time (s) 
to healthcare workers and the patients' relatives. Furthermore, the developed system is more economical, comfortable, and convenient than existing systems not only for the patients, but also for the doctors. The patients can easily use this device in their home environment. This study aims to design a remote monitoring system for sleep apnea to ensure patient safety and ease the workload of doctors in the Covid19 era. It is believed that the hardware approach we propose could be a useful tool to study the population in their home.

As future work, the monitoring system will be extended with the incorporation of new services and biosensors (to view values in graphs). As a further study, developed system is planned to use at hospitals to eliminate the possible side effects encountered in practice.

Acknowledgements The authors thank the reviewers and the editors of Journal of Medical \& Biological Engineering \& Computing. We would also like to thank the Ondokuz Mayıs University Health Application and Research Center Sleep Laboratory service staff for their help and contributions. (Note: This laboratory has been accredited as "Education laboratory" by the Sleep Association, Ankara, TURKEY, 2020).

Funding: This study was supported by the Coordinatorship of Ondokuz May1s University's Scientific Research Projects (Project Number: PYO. YMY.1901.20.001), Samsun, Turkey.

\section{Declarations}

Ethical approval All procedures performed in studies involving human participants were by the ethical standards of the institutional and national research committee and with the 1964 Helsinki declaration and its later amendments or comparable ethical standards.

Conflict of Interest The authors declare that they have no conflict of interest.

Informed consent Informed consent was obtained from all individual participants included in the study.

\section{References}

1. Ayoub G, Dang TH, Oh TI, Kim SW, Woo EJ (2020) Feature Extraction of Upper Airway Dynamics during Sleep Apnea using Electrical Impedance Tomography. Sci Rep 10:1637. https://doi. org/10.1038/s41598-020-58450-4

2. Cisonni J, Lucey AD, King AJC, Islam SMS, Lewis R, Goonewardene MS (2015) Numerical simulation of pharyngeal airflow applied to obstructive sleep apnea: effect of the nasal cavity in anatomically accurate airway models. Med Biol Eng Comput 53:1129-1139. https://doi.org/10.1007/s11517-015-1399-z

3. Kim JW, Kwon SO, Lee WH (2020) Nocturnal heart rate variability may be useful for determining the efficacy of mandibular advancement devices for obstructive sleep apnea. Sci Rep 10:1030. https://doi.org/10.1038/s41598-020-57780-7

4. Bauters FA, Loof S, Hertegonne KB, Chirinos JA (2020) Buyzere, M. L. D.; Rietzschel, E. R. Sex-specific sleep apnea screening questionnaires: closing the performance gap in women, Sleep Medicine 67:91-98. https://doi.org/10.1016/j.sleep.2019.10.023

5. Saha S, Kabir M, Ghahjaverestan NM, Hafezi M, Gavrilovic B, Zhu K, Alshaer H, Yadollahi A (2020) Portable diagnosis of sleep apnea with the validation of individual event detection. Sleep Med 69:51-57. https://doi.org/10.1016/j.sleep.2019.12.021

6. Kato K, Noda A, Yasuma F, Matsubara Y, Miyata S, Iwamoto K, Miyazaki M, Ozaki N (2020) Effects of sleep-disordered breathing and hypertension on cognitive function in elderly adults. Clin Exp Hypertens 42(3):250-256. https://doi.org/10.1080/10641963. 2019.1632338

7. Tork MA, Rashed HR, Elnabil L, Salah-Eldin N, Elkhayat N, Abdelhady AA, Abdulghani MO, Abdulghani KO (2020) Sleep pattern in epilepsy patients: a polysomnographic study. Egypt J Neurol Psychiatry Neurosurg, 56(5). https://doi.org/10.1186/ s41983-019-0141-4

8. Bailly S, Galerneau LM, Ruckly S, Seiller A, Terzi N, Schwebel C, Dupuis C, Tamisier R, Mourvillier B, Pepin JL, Timsit JF (2020) Impact of obstructive sleep apnea on the obesity paradox in critically ill patients. J Crit Care 56:120-124. https://doi.org/ 10.1016/j.jcrc.2019.12.016

9. Alonso-Fernandez A, Toledo-Pons N, García-Río F (2020) Obstructive sleep apnea and venous thromboembolism: Overview of an emerging relationship. Sleep Med Rev 50:101233. https:// doi.org/10.1016/j.smrv.2019.101233

10. Orjuela-Cañón AD, Cerquera A, Freund JA, Juliá-Serdá G, Ravelo-García AG (2020) Sleep apnea: Tracking effects of a first session of CPAP therapy by means of Granger causality. Comput Methods Programs Biomed 187:105235. https://doi.org/10.1016/j. cmpb.2019.105235

11. Strausz S, Kiiskinen T, Broberg M, Ruotsalainen S, Koskela J, Bachour A, Gen F, Palotie A, Palotie T, Ripatti S, Ollila HM (2021) Sleep apnoea is a risk factor for severe COVID-19. BMJ Open Resp Res 8:e000845. https://doi.org/10.1136/bmjre sp-2020-000845

12. Maas MB, Kim M, Malkani RG, Abbott SM, Zee PC (2020) Obstructive sleep apnea and risk of COVID-19 infection, hospitalization and respiratory failure. Sleep Breath 25(2):1155-1157. https://doi.org/10.1007/s11325-020-02203-0

13. Cade BE, Dashti HS, Hassan SM, Redline S, Karlson EW (2020) Sleep apnea and COVID-19 mortality and hospitalization. Am J Respir Crit Care Med 202(10):1462-1464. https://doi.org/10. 1164/rccm.202006-2252LE

14. Oh TK, Song IE (2021) Impact of coronavirus disease-2019 on chronic respiratory disease in South Korea: an NHIS COVID-19 database cohort study. BMC Pulm Med 21:12. https://doi.org/10. 1186/s12890-020-01387-1

15. Miller MA, Cappuccio FP (2021) A systematic review of COVID19 and obstructive sleep apnoea. Sleep Med Rev 55:101382. https://doi.org/10.1016/j.smrv.2020.101382

16. Naime $S$, Weiss M, Nino G (2021) Effects of COVID-19 pandemic on adherence to obstructive sleep apnea therapy: A case report. Clin Case Rep 9:12-14. https://doi.org/10.1002/ccr3.3363

17. Coma-Del-Corral MJ, Alonso-'Alvarez, ML, Allende M, Cordero J, Ordax E, Masa F, Ter'an-Santos J, (2013) Reliability of telemedicine in the diagnosis and treatment of sleep apnea syndrome. Telemedicine and e-Health 19(1):7-12. https://doi.org/10.1089/ tmj.2012.0007

18. Al-Zubaidie M, Zhang Z, Zhang J. PAX: Using Pseudonymization and Anonymization to Protect Patients' Identities and Data in the Healthcare System. International Journal of Environmental Research and Public Health. 2019;16(9). https://doi.org/10.3390/ ijerph16091490.

19. Rivero-García A, Santos-González I, Hernández-Goya C, Caballero-Gil P, Yung M (2017) Patients' Data Management System Protected by Identity-Based Authentication and Key Exchange. 
Sensors (Basel, Switzerland) 17(4):733. https://doi.org/10.3390/ s17040733

20. Alevtina Dubovitskaya, Visara Urovi, Matteo Vasirani, Karl Aberer, Michael Schumacher. A CloudBased eHealth Architecture for Privacy Preserving Data Integration. 30th IFIP International Information Security Conference (SEC), May 2015, Hamburg, Germany. pp.585-598, https://doi.org/10.1007/978-3-319-184678_39ff. ffhal-01345150f.

21. Drummond M (2020) Sleep labs, lung function tests and COVID-19 pandemic e only emergencies allowed. Pulmonology 26(4):244-245. https://doi.org/10.1016/j.pulmoe.2020.04.002

22. Başçiftçi F, İncekara H (2011) Web Based Medical Decision Support System Application Of Coronary Heart Disease Diagnosis With Boolean Functions Minimization Method Expert Systems with Applications, ISSN: 0957-4174, 38(11): 14037-14043. https://doi.org/10.1016/j.eswa.2011.04.211

23. Takagi T, Nakamura K, Hashimoto H, Asami M, Ishii R, Enomoto I, Moroi M, Noro M, Sugi K, Nakamura M (2020) The impact of sleep apnea on right atrial structural remodeling with atrial fibrillation. J Cardiol 75(6):665-672. https://doi.org/10.1016/j. jjcc.2019.12.012

24. Kouri J, Kolla BP, Morgenthaler TI, Mansukhani MP (2020) Frequency and outcomes of primary central sleep apnea in a population-based study. Sleep Med 68:177-183. https://doi.org/10. 1016/j.sleep.2019.12.008

25. Pombo N, Garcia N, Bousson K (2017) Classification techniques on computerized systems to predict and/or to detect Apnea: A systematic review. Comput Methods Programs Biomed 140:265-274. https://doi.org/10.1016/j.cmpb.2017.01.001

26. Zambotti M, Baker FC, Willoughby AR, Godino JG, Wing D, Patrick K, Colrain IM (2016) Measures of sleep and cardiac functioning during sleep using a multi-sensory commercially-available wristband in adolescents. Physiol Behav 158:143-149. https://doi. org/10.1016/j.physbeh.2016.03.006

27. Al-Mardini M, Aloul F, Sagahyroon A, Al-Husseini L (2014) Classifying obstructive sleep apnea using smartphones. J Biomed Inform 52:251-259. https://doi.org/10.1016/j.jbi.2014. 07.004

28. Gutierrez-Tobal GC, Alonso-Alvarez ML, Alvarez D, Campo F, Teran-Santos J, Hornero R (2015) Diagnosis of pediatric obstructive sleep apnea: Preliminary findings using automatic analysis of airflow and oximetry recordings obtained at patients' home. Biomed Signal Process Control 18:401-407. https://doi.org/10. 1016/j.bspc.2015.02.014

29. Michelet M, Blanchon S, Guinand S, Ruchonnet-Metrailler I, Mornand A, Van HC, Barazzone-Argiroffo C, Corbelli R (2020) Successful home respiratory polygraphy to investigatesleep-disordered breathing in children. Sleep Med 68:146-152. https://doi. org/10.1016/j.sleep.2019.11.1264

30. Yadollahi A, Giannouli E (2010) Moussavi Z (2010) Sleep apnea monitoring and diagnosis based on pulse oximetery and tracheal sound signals. Med Biol Eng Comput 48:1087-1097. https://doi. org/10.1007/s11517-010-0674-2

31. McCullagh P, Carswell W, Mulvenna M, Augusto Wrede JC, Zheng H, Jeffers W (2011) Nocturnal sensing and intervention for assisted living of people with dementia. Healthcare Sensor Networks: Challenges Toward Practical Implementation Chapter 11:283. https://doi.org/10.1201/b11195-12

32. Min SD, Yoon DJ, Yoon SW, Yun YH, Lee M (2007) A study on a non-contacting respiration signal monitoring system using Doppler ultrasound. Med Bio Eng Comput 45:1113-1119. https:// doi.org/10.1007/s11517-007-0246-2

33. Ruiz-Zafra A, Noguera M, Benghazi K, Garrido JL, Urbano GC, Caracuel A (2013) A mobile cloud-supported e-rehabilitation platform for brain-injured patients, 2013 7th International Conference on Pervasive Computing Technologies for Healthcare and
Workshops, Venice, Italy, pp. 352-355. https://doi.org/10.4108/ icst.pervasivehealth.2013.252308

34. Zhang J, Zhang Q, Wang Y, Qiu C (2013) A real-time auto-adjustable smart pillow system for sleep apnea detection and treatment. In: Proceedings of the $12^{\text {th }}$ international conference on Information processing in sensor networks. 179-190. https://doi.org/10. $1145 / 2461381.2461405$

35. Nakano H, Hirayama K, Sadamitsu Y, Toshimitsu A, Fujita H, Shin S, Tanigawa T (2014) Monitoring sound to quantify snoring and sleep apnea severity using a smartphone: proof of concept. Journal of clinical sleep medicine: J Clin Sleep Med 10(1):73-78. https://doi.org/10.5664/jcsm.3364

36. Isetta V, Montserrat JM, Thiebaut $G$, Weber C, Navajas D, Farre R (2013) A new device for sleep apnea treatament telemonitoring: a bench study. International Journal On Advances in Life Sciences, 5(3):250-259. ISSN: 1942-2660

37. Iovanovici A, Topirceanu A, Udrescu M, Prodan L, Mihaicuta S (2015) A high-availability architecture for continuous monitoring of sleep disorders. Studies in health technology and informatics 210:729-733. https://doi.org/10.3233/978-1-61499-512-8-729

38. Bsoul M, Minn H, Tamil L (2011) Apnea MedAssist: Real-time Sleep Apnea Monitor Using Single-Lead ECG. IEEE Trans Inf Technol Biomed 15(3):416-427. https://doi.org/10.1109/TITB. 2010.2087386

39. Al-Naji A, Al-Askery AJ, Gharghan SK, Chahl J (2019) A System for Monitoring Breathing Activity Using an Ultrasonic Radar Detection with Low Power Consumption. J Sens Actuator Netw 8(2):32. https://doi.org/10.3390/jsan8020032

40. Gharghan SK, Fakhrulddin SS, Al-Naji A, Chahl J (2019) EnergyEfficient Elderly Fall Detection System Based on Power Reduction and Wireless Power Transfer. Sensors 19(20):4452. https://doi. org/10.3390/s19204452

41. Balderas-Díaz S, Benghazi K, Garrido J, Guerrero-Contreras G, Miró E (2015) Designing New Low-Cost Home-Oriented Systems for Monitoring and Diagnosis of Patients with Sleep ApneaHypopnea. ICTs for Improving Patients Rehabilitation Research Techniques. REHAB 2014. Communications in Computer and Information Science, 515:210-221. Berlin, Heidelberg. https://doi. org/10.1007/978-3-662-48645-0_18

42. Yüzer AH, Sümbül H, Polat K (2020) A Novel Wearable RealTime Sleep Apnea Detection System Based on the Acceleration Sensor. IRBM 41(1):39-47. https://doi.org/10.1016/j.irbm.2019. 10.007

43. Yüzer AH, Sümbül H, Nour M, Polat K (2020) A different sleep apnea classification system with neural network based on the acceleration signals. Appl Acoust 163:107225. https://doi.org/ 10.1016/j.apacoust.2020.107225

44. Jagannath M, Mohan CM, Kumar A, Aswathy MA, Nathiya N (2019) Design and testing of a spirometer for pulmonary functional analysis. International Journal of Innovative Technology and Exploring Engineering. 8:343-347, ISSN: 2278-3075.

45. Rongxia S, Yi T, Yibing D (2009) Design and Implementation of Industrial Multi-Parameter Data Acquisition System Based on AT89S52. Third International Symposium on Intelligent Information Technology Application Workshops, 169-172. https://doi.org/ 10.1109/IITAW.2009.11

46 Yusof MA, Xin FS, Low WL, Lim CW, Hau YW (2019) Miniaturized and Portable Home-Based Vital Sign Monitor Design with Android Mobile Application. International Journal of Integrated Engineering 11(3):10-12. https://doi.org/10.30880/ijie.2019.11. 03.002

47. Prakash R, Ganesh AB, Sivabalan S (2017) Network Coded Cooperative Communication in a Real-Time Wireless Hospital Sensor Network. J Med Syst 41:72. https://doi.org/10.1007/ s10916-017-0721-8 
48. Saçan KB, Ertaş G (2017) Performance Assessment of MAX30100 SpO2/Heartrate Sensor, Conference Proceedings, Medical Technologies National Congress (TIPTEKNO), Publisher: IEEE, pp: 389-392. https://doi.org/10.1109/TIPTEKNO. 2017.8238126

49. Yin W, Zhang H, Zhong T, Min X (2018) A Novel Compact DualBand Frequency Selective Surface for GSM Shielding by Utilizing a 2.5-Dimensional Structure. IEEE Transactions on Electromagnetic Compatibility 60(6):2057-2060. https://doi.org/10.1109/ TEMC.2018.2790584

50. Yadav S, Jain CP, Sharma MM (2019) Smartphone Frequency Shielding With Penta-Bandstop FSS for Security and Electromagnetic Health Applications. IEEE Trans Electromagn Compat 61(3):887-892. https://doi.org/10.1109/TEMC.2018.2839707

51. Mishra G, Kaavya D (2017) Interfacing atmospheric variables to web interface using arduino," 2017 International Conference on Algorithms, Methodology, Models and Applications in Emerging Technologies (ICAMMAET), Chennai, pp. 1-6, doi: https://doi. org/10.1109/ICAMMAET.2017.8186709

Publisher's Note Springer Nature remains neutral with regard to jurisdictional claims in published maps and institutional affiliations.

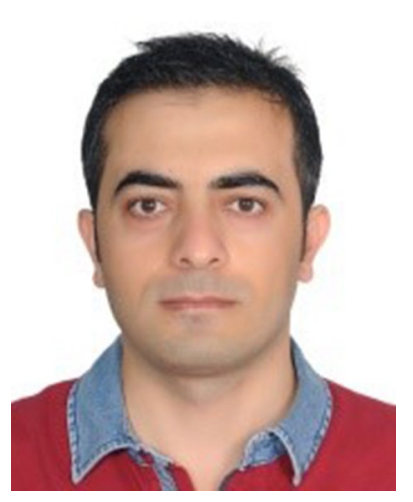

Harun SÜMBÜL received B.S. degree in Electronic sciences from the Selçuk University, Konya, Turkey, in 2008, the M.S. degree from the Selçuk University from Electrical and Electronics Engineering, Konya, Turkey, in 2011, and received the $\mathrm{PhD}$ degree in Electrical and Electronics Engineering from Karabük University, Karabük, in 2017, Turkey. His primary areas of research are biomedical engineering and biomedical signal processing. He is currently a Lecturer at the Yeşilyurt Demir
Çelik Vocational School, department of biomedical device technologies at Ondokuz Mayıs University, Turkey.

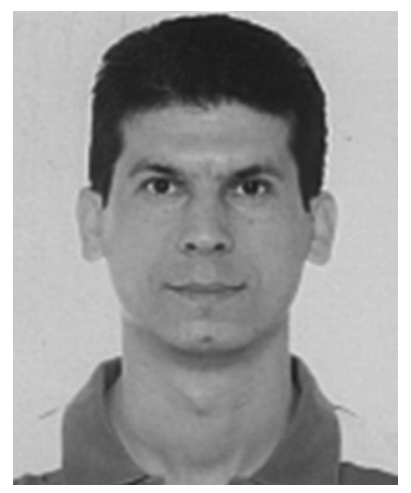

A. Hayrettin YÜZER received B.S. degree in Electrical and Electronic Engineering from İnönü University, Malatya, Turkey, in 1999, the M.S. degree from İnönü University for Electrical and Electronics Engineering, Malatya, Turkey, in 2002, and received the $\mathrm{PhD}$ degree in Electrical and Electronics Engineering from Middle East Technical University (METU), Ankara, Turkey, in 2011. He is currently an Associate Professor in Electrical and Electronics EngineerKarabük, Turkey. ing from the Karabük University,

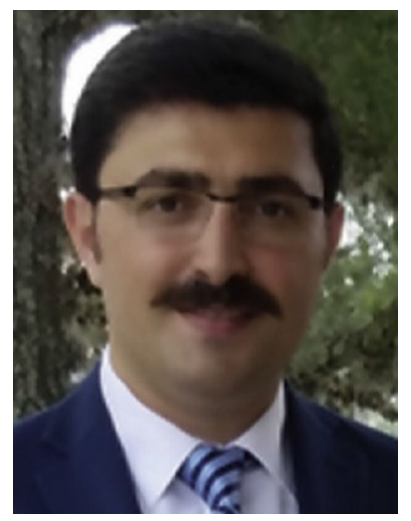

Kazım Şekeroğlu received B.S. degree in electronics and computer education from Gazi University, Ankara, Turkey, in 2007, M.S. degree in Electrical Engineering from Southern University and A\&M College, Baton Rouge, LA, in 2011, and PhD degree in electrical engineering from Louisiana State University, Baton Rouge, LA, in 2017. He is now an Assistant Professor in computer science and industrial technology at Southeastern Louisiana University, Hammond, LA. His research interests are computer vision, image processing, and data analysis.

\section{Authors and Affiliations}

\section{Harun SÜMBÜL ${ }^{1}$ - Ahmet Hayrettin YÜZER ${ }^{2}$ - Kazım Şekeroğlu ${ }^{3}$}

Ahmet Hayrettin YÜZER

hayrettinyuzer@karabuk.edu.tr

Kazım Şekeroğlu

kazim.sekeroglu@selu.edu

1 Yesilyurt D.C. Vocational School, Ondokuz Mayis University, Samsun, Turkey
2 Department of Electrical and Electronics Engineering, Karabuk University, Karabuk, Turkey

3 Department of Computer Science, Southeastern Louisiana University, Hammond, Louisiana, USA 